\title{
O lugar da Vigilância Socioassistencial na trajetória da política de Assistência Social
}

The place of social security surveillance in the trajectory of the Social Assistance policy

\author{
Caio Cesar Cunha* \\ Ideni Terezinha Antonello**
}

\begin{abstract}
Resumo
Em tempos de desmonte das políticas sociais cria-se a necessidade de efetuar uma releitura do rumo percorrido e apontar possíveis caminhos que podem servir de instrumento capaz de viabilizar a mudança. A Vigilância Socioassistencial, se efetivada, pode gerar ferramentas de gestão capazes de confrontar com informações que não estão visíveis aos gestores. Quando a informação se representa cartograficamente, há um aumento das possibilidades de planejamento e viabilização das tomadas de decisão. Dessa forma, mediante a levantamento de material bibliográfico, o objetivo da presente produção é descrever a trajetória da política de Assistência Social até os dias atuais com a intenção de ressaltar a importância da Vigilância Socioassistencial. Ter a noção de espacialidade do território é muito mais que uma simples noção de localização, é aprimorar o olhar estratégico sobre o território e identificar as demandas mais urgentes a que os sujeitos estão expostos. É sair do global e chegar ao local.
\end{abstract}

Palavras-chave: Assistência Social; Território; Vigilância Socioassistencial; Políticas Sociais; Gestão.

\begin{abstract}
In times of dismantling social policies creates the need to carry out a re-reading of the course taken and to point out possible ways that can serve as an instrument capable of making change possible. The Socioassistential Surveillance if carried out can generate management tools able to confront with information that is not visible to the managers. When the information is represented cartographically, it increases the possibilities of planning and makes possible the decision making. To this end, through the collection of bibliographical material, the objective of the present production is to describe the trajectory of the Social Assistance policy to the present day with the intention of highlighting the importance of Surveillance. To have the notion of spatiality of the territory is much more than a simple notion of location, is to improve the strategic look on the territory and to identify the most urgent demands that the subjects are exposed. It's getting out of the global and getting to the place.
\end{abstract}

Keywords: Social assistance; Territory; Social Assistance Surveillance; Social politics; Management.

\footnotetext{
* Doutorando do programa de Pós-Graduação em Geografia pela Universidade Estadual de Londrina.

** Doutora em Geografia pela Universidade Estadual Paulista Júlio de Mesquita Filho. Docente da Universidade Estadual de Londrina.
} 


\section{Introdução}

As políticas públicas no Brasil de âmbito social tiveram uma trajetória um tanto quanto longa e demorada em relação à demanda que o país sempre apresentou. O Brasil, um país periférico capitalista, entrou no mundo industrial a partir da década de 1930. O Estado é que teve o papel de alavanca desse processo e as políticas econômicas eram basicamente voltadas para a indústria situada no crescente espaço urbano - controlando também o latifúndio no campo. Naquele momento, o padrão brasileiro de políticas sociais estava baseado na "cidadania regulada" - conceito cujas raízes encontram-se não em código de valores políticos, mas em um sistema de estratificação ocupacional, e que, além disso, era definido como norma legal.

A "cidadania regulada", de acordo com Santos (1979), regrava quem era ou não cidadão. Eram cidadãos todas aquelas pessoas da comunidade que se encontravam em qualquer uma das ocupações reconhecidas e definidas em lei, isto é, aqueles que possuíam registro e carteira de trabalho. A cidadania estava embutida na profissão e os direitos do cidadão restringiam-se ao direito do lugar que ocupa no processo produtivo, tal como reconhecido por lei. Este modelo de política social atravessou a ditadura Vargas, o período populista e a longa ditadura militar. Por este longo período, mais especificamente de 1930 até 1984, o Estado entendeu que os cidadãos eram apenas os sujeitos que estavam dentro do padrão por ele instituído, suas ações eram inteiramente limitadas. Isso só sofreu modificações após a promulgação da Constituição Federal de 1988. A maior justificativa do distanciamento do Estado aos cidadãos nessa época se dá em relação à política limitada que era imposta aos gestores e a população. Hoje, o cenário é outro, apesar de muitos avanços e conquistas, ainda contam-se com ações limitantes na gestão territorial das políticas sociais no país.

Considerando o desmonte das políticas públicas direcionadas às minorias, objetivase no presente artigo analisar os avanços conquistados pela sociedade e compreender os aperfeiçoamentos adquiridos pela Política de Assistência Social. Para atingir esse escopo foi necessário realizar, no processo metodológico, uma revista histórica da transformação da Política de Assistência Social por meio de produções acadêmicas, cartilhas e documentos oficiais elaborados até a contemporaneidade, sendo fundamental dividir o artigo em importantes marcos históricos que apontam as principais conquistas da Política sob o contexto de desenvolvimento territorial. Observam-se que métodos de gestão territorial 
estão caminhando para um aprimoramento da percepção e interpretação das territorialidades cada vez mais subjetivas e distantes da compreensão dos técnicos.

No sentido que a visão interdisciplinar na gestão territorial ganha força, a Geografia pode contribuir para fazer aflorar as territorialidades da sociedade e dar voz ativa à população que demanda às políticas púbicas, visando uma cidadania de emancipação e promovendo maior autonomia ao cidadão. Com levantamento e análise das principais legislações desde a Constituição cidadã de 1988, procura-se estabelecer uma linha cronológica que possibilite identificar importantes avanços nas políticas sociais brasileiras e, com isso, apontar as questões responsáveis que possibilitaram o alcance de uma (re)organização das políticas públicas de âmbito social no histórico brasileiro.

\section{A Assistência Social e a Constituição Federal de 1988}

Conhecida como constituição cidadã, a CF 1988 foi marcada por uma série de modificações profundas no campo social e da cidadania. A legislação brasileira nem sempre previa a adoção de medidas assistenciais para a proteção de cidadãos em situação de risco e vulnerabilidade, a CF 1988 foi a primeira a trazer em seu conteúdo essa preocupação. As outras constituições e normas legais mencionavam apenas o acesso à previdência social ou à saúde, nenhuma citava a Assistência Social.

A Constituição inova em aspectos técnicos e político-administrativos no que se refere à descentralização, altera as normas e regras centralizadoras e distribui melhor as competências entre o Poder Central da União com os poderes regionais (estados) e locais (municípios). Além disso, traz prerrogativas que visa o incentivo ao estímulo da participação da sociedade civil na elaboração e monitoramento das políticas públicas.

A CF 1988, segundo Giaqueto (2010) no que se trata da questão social, introduz um conceito novo de seguridade social que inclui o tripé: Saúde, Previdência e Assistência Social. Com esta noção em centro, é suposto que os cidadãos tenham acesso a um conjunto de seguranças que cubra, reduza ou previna situações de risco como de vulnerabilidades pessoais e sociais.

Porém, mesmo com toda conquista social, nos anos 1990 ocorre um desmonte social novamente com a entrada do governo neoliberal, que se espalhou no Brasil e em outros países, com seu projeto de reajuste fiscal causando impacto em boa parcela da população que estava começando a receber um mínimo de atenção do Estado. Neste momento, a economia 
sofria grandes oscilações e intensos processos de desregulamentação, o governo Collor (1990 - 1992), na tentativa de solucionar o problema, adotou a política de Estado máximo para o capital e mínimo para o social. Incentivou a reestruturação de empresas e passou grande parte das funções de obrigação do Estado para empresas privadas.

Na Constituição de 1988, a Seguridade Social é compreendida como um conjunto integrado de ações de iniciativa dos poderes públicos e da sociedade, destinadas a assegurar os direitos relativos à Saúde, à Previdência e à Assistência. Pereira destaca que:

[...] o governo Collor fragmentou a Seguridade Social em ministérios diferentes, dando-lhe margem para realizar, na Saúde, um boicote orçamentário sistemático ao SUS. Na Previdência, lançou um pacote de reforma previdenciária já em 1992, cuja função era retirar direitos dos trabalhadores conquistados na CF 1988. Na Assistência, vetou a LOAS, desrespeitando a CF 1988 (PEREIRA, 2010, p.5).

Fica evidente a intensa luta que a sociedade teve que enfrentar nos anos 1990, não só na Assistência, mas na Saúde e na Previdência. A CF 1988 promove a inserção da Assistência Social no sistema de Seguridade Social, que teria como objetivo possibilitar que os cidadãos tivessem acesso ao conjunto de seguranças, que cobriria e reduziria as situações de risco, bem como preveniria ocorrências de vulnerabilidades pessoais e sociais. Os dois artigos mais relevantes em relação à Assistência Social são os 203 e 204, os quais relacionam seus objetivos de proteção e amparo e suas ações de descentralização dos serviços e participação da população.

Nesse contexto, destaca-se que a política de Assistência Social, para conquistar categorias mínimas de efetividade em suas urgências, precisa ser descentralizada. Com essa dissociação do poder entre as esferas governamentais e locais, há ganho na gestão e aumento das relações entre sociedade-Estado, promovendo diversos desdobramentos que tangem uma reforma mais efetiva em que há participação da população, tal como reformulações das políticas de proximidade, o que proporciona maior contato com a realidade presente em cada território. Antonello conclui que:

A contraposição à centralização do poder assenta-se na concepção moderna do federalismo que defende a potencialidade de intervenção dos governos locais em prol do atendimento direto à população, pautado na premissa que a proximidade da população promoveria um controle social das políticas públicas (ANTONELLO, 2012, p. 834). 
A CF 1988, teoricamente, fortalece as ações da Assistência como política pública. Mas, para concretização e regulação de todas suas diretrizes, seria necessária a Lei Orgânica de Assistência Social (LOAS) que, segundo Giaqueto:

[...] introduz uma nova forma de discutir a questão da Assistência Social, substituindo a visão centrada na caridade e no favor. É o instrumento que regulamenta os pressupostos constitucionais, ou seja, o conteúdo da Constituição Federal em seus artigos 203 e 204, que definem e garantem os direitos à assistência social. Assim, a LOAS inova ao conferir à assistência social o status de política pública, direito do cidadão e dever do Estado. Inova também pela garantia da universalização dos direitos sociais e por introduzir o conceito dos mínimos sociais (GIAQUETO, 2010, p.80).

A Lei Orgânica da Assistência Social (LOAS), Lei no 8.742, de 7 de dezembro de 1993, tem por objetivo garantir uma política de proteção a quem necessita:

A LOAS preconiza que a gestão da política e a organização das ações devem ser articuladas em um sistema descentralizado e participativo, organizado nos três níveis de gestão governamental. Assim, a regulamentação da Assistência Social a define como competência das três esferas de governo e, por sua vez, a sua implementação torna-se tarefa explicitamente compartilhada entre os entes federados autônomos (BRASIL, 2004, p. 82).

É evidente a necessidade da aprovação da LOAS que regulamenta os pressupostos constitucionais pois, desse modo, oferece o amparo e a legitimidade a todo o conteúdo destacado nos artigos 203 e 204 da CF 1988, bem como a condição de política pública, destarte, fica garantido por lei todos os direitos dos cidadãos à assistência social.

Porém, foi só no ano de 1993, com as grandes mobilizações sociais e o impeachment de Fernando Collor de Melo, que Itamar Franco assume e sanciona a LOAS - o que não foi motivo para o rompimento do governo neoliberal.

Em 1995, Fernando Henrique Cardoso assume a presidência da República e acaba de concretizar a política neoliberal. Sem se aprofundar na questão política operada pelo chamado "Terceiro Setor", no plano social foi realizado um desmonte, questões fundamentais que haviam sido conquistadas desde a década de 1930 foram desfeitas no governo de FHC. No entanto, alguns Programas Sociais ainda foram criados. Em 1995, foi o Programa Comunidade Solidária, que não condizia com o estabelecido na LOAS e ainda recebia recursos sem o devido controle social do Conselho Nacional de Assistência Social ${ }^{1}$, deixando, ainda, a marca de

\footnotetext{
${ }^{1}$ O Conselho Nacional de Assistência Social - CNAS foi instituído pela Lei Orgânica da Assistência Social - LOAS Lei no 8742, de 07 de dezembro de 1993 (BRASIL, 2016).
} 
política assistencialista. No mesmo foco, outros programas surgiram. Em 1996, foi executado o Programa de Erradicação do Trabalho Infantil (Peti); em 1999, o Programa Comunidade Ativa; e em 2000, o Projeto Alvorada que mais tarde se tornou o Fome Zero. Contudo, mesmo criando Programas Sociais, ao analisar e avaliar a trajetória do governo de FHC, Oliveira (2003) salienta que foram realizadas ações pulverizadas, sem garantia de continuidade e que as decisões foram executadas em nível federal e foi repassada grande carga de responsabilidade para o nível municipal.

Nota-se que grande parte do problema se encontra nas ações fragmentadas e nas decisões verticais de cima para baixo. A impossibilidade de continuidade nos programas sociais gera esgotamento na gestão em nível municipal e a inviabilidade estrutural de funcionamento das ações objetivadas. O governo FHC não só deixou de cumprir com o definido em lei, como ignorou a necessidade de construção do SUAS (Sistema Único de Assistência Social) para que as condições indicadas na CF 1988 e na LOAS fossem realmente concretizadas e colocadas em prática.

\section{Trajetória da política nacional: Assistência Social com foco no território}

Foram décadas difíceis para as políticas sociais com a predominância do governo neoliberal no Brasil. Nas eleições de 2002, a conquista do governo liderada por Luiz Inácio Lula da Silva passa a dar ênfase na tentativa de uma maior integração das políticas sociais no que se refere à reestruturação dos programas e da participação da sociedade e, com isso, foram elaboradas diversas conferências que contemplavam todos os níveis de gestão. A mudança mais expressiva foi discutida na IV Conferência Nacional de Assistência Social, que aprovou a Política Nacional de Assistência Social (PNAS), em 2004. Por meio da Secretaria Nacional de Assistência Social, o Ministério do Desenvolvimento Social e Combate à Fome (MDS) torna pública a versão final dessa política que é intitulada de PNAS/2004.

Como já mencionado a relevância da LOAS, é importante caracterizar a PNAS que, em consenso com a Lei Orgânica, traz em seus princípios democráticos:

\footnotetext{
I - Supremacia do atendimento às necessidades sociais sobre as exigências de rentabilidade econômica;

II - Universalização dos direitos sociais, a fim de tornar o destinatário da ação assistencial alcançável pelas demais políticas públicas;

III - Respeito à dignidade do cidadão, à sua autonomia e ao seu direito aos benefícios e serviços de qualidade, bem como à convivência familiar e comunitária, vedandose qualquer comprovação vexatória de necessidade;
} 
IV - Igualdade de direitos no acesso ao atendimento, sem discriminação de qualquer natureza, garantindo-se equivalência às populações urbanas e rurais;

V - Divulgação ampla dos benefícios, serviços, programas e projetos assistenciais, bem como dos recursos oferecidos pelo Poder Público e dos critérios para sua concessão (BRASIL, 2004, p.32).

Nota-se um maior aprofundamento nos deveres do Estado bem como maior amparo aos direitos e dignidade do cidadão. No mesmo documento, ao se verificar as normativas da PNAS, destacam-se seus principais objetivos:

- prover serviços, programas, projetos e benefícios de proteção social básica e, ou, especial para famílias, indivíduos e grupos que deles necessitarem.

- contribuir com a inclusão e a equidade dos usuários e grupos específicos, ampliando o acesso aos bens e serviços socioassistenciais básicos e especiais, em áreas urbana e rural.

- assegurar que as ações no âmbito da assistência social tenham centralidade na família, e que garantam a convivência familiar e comunitária (BRASIL, 2004, p. 33).

É possível observar a atenção de cunho local que o texto adquire quando menciona a ampliação do acesso aos bens e serviços socioassistenciais básicos e especiais em áreas urbana e rural, bem como assegura que todos esses serviços sejam realizados com centralidade na família e sua convivência comunitária.

Em seu texto, o PNAS institui o SUAS (Sistema Único da Assistência Social), requisito essencial também mencionado na LOAS que dá a efetividade à Assistência Social como política pública e aborda todas as questões relacionadas à gestão, desde os recursos financeiros até a aplicabilidade e operacionalização das ações dos serviços socioassistenciais.

Os pressupostos constitucionais da Assistência Social se concretizam com a PNAS e consequentemente com o SUAS, ao definir as diretrizes, princípios, estratégias e formas de gestão pois, assim, estabelece um instrumento de gestão com ações diretas, efetivando as competências tal como os fluxos entre as esferas Federal, Estadual e Municipal.

Assim, é relevante destacar que a Norma Operacional Básica (NOB-SUAS/2005) do Sistema Único da Assistência Social, publicada no PNAS/2004 em novembro de 2005, apenas no ano de 2011 , com a aprovação da Lei no 12.435 , alterou os dispositivos da Lei $n$ o 8.742/93 da LOAS.

A NOB-SUAS/2005 representou um marco fundamental na estruturação da Política Pública de Assistência Social, imprimindo um grande salto quantitativo na implantação de serviços socioassistenciais em todo o território nacional, tendo como base critérios de partilha transparentes e objetivos, adequados à distribuição territorial das populações vulneráveis, com a alocação equitativa do cofinanciamento federal e a possibilidade de superação das distorções regionais históricas (NOB-SUAS, 2012, p.13). 
A NOB-SUAS não só representou um marco na estruturação da Política Pública de Assistência Social como guiou a política no quesito aplicabilidade e operacionalização do gerenciamento dos serviços.

A NOB-SUAS é um compromisso de todos os entes federativos, e assegura única concepção em todo território nacional. Garante, ainda, questões regulatórias do Estado sobre a atividade pública, cuja prática democrática sob o controle social prevê a participação da população e da sociedade na formulação e controle das ações e o comando único das ações em cada esfera do governo.

A partir dessa concepção, apresenta-se um sistema efetivo de gestão. O SUAS é um sistema público não contributivo, descentralizado e participativo que tem por função a gestão do conteúdo específico da Assistência Social no campo da proteção social brasileira (BRASIL, 2004).

Além dos termos gerais que cria e regula os objetivos traçados pelo sistema, a gestão do SUAS se estrutura nos seguintes itens:

\footnotetext{
a. Precedência da gestão pública da política;

b. Alcance de direitos socioassistenciais pelos usuários;

c. Matricialidade sociofamiliar;

d. Territorialização;

e. Descentralização político-administrativa;

f. Financiamento partilhado entre os entes federados;

g. Fortalecimento da relação democrática entre estado e sociedade civil;

h. Valorização da presença do controle social;

i. Participação popular/cidadão usuário;

j. Qualificação de recursos humanos;

k.Informação, monitoramento, avaliação e sistematização de resultados (BRASIL, 2004, p.87).
}

Ao analisar o objetivo geral e os itens que estruturam o Sistema Único, é possível observar que ao se discutir a gestão descentralizada, intrinsecamente remete-se ao território e aos atores que o constroem. Em todos os casos são citadas formas operacionais de gestão, mas sempre são antecedidas pela compreensão do território e suas diversidades.

A contribuição da Assistência Social nessa perspectiva, implementada como política pública afiançadora de direitos, deve-se realizar por meio de uma estrutura políticoadministrativa que ressalte a fundamental relevância do processo de descentralização, quanto ao redesenho do papel e da escala espacial de organização dos serviços do Estado Brasileiro, que possa facilitar a transferência, em blocos de competências, das ações para os territórios mais próximos da população e de suas necessidades [...] (BRASIL, 2004, p.89). 
No âmbito do SUAS e da política descentralizada no território, para a Assistência Social garantir-se como uma política pública afiançadora de direitos, o foco tem de ser transferido para a menor escala de análise disponível, identificando as famílias e seus membros a partir de seus territórios de vivência, pois, esse é o modo mais eficiente de interpretar a realidade da localidade em questão e identificar as demandas, sempre dando prioridade àquelas situações com os maiores registros de fragilidades e vulnerabilidades.

É dentro dessa perspectiva que surge a necessidade de relacionar as pessoas aos seus respectivos territórios, bem como aplicar metodologias que encontrem as demandas sociais que estão ocultadas e que ainda não foram identificadas. Por mais que os serviços da Assistência Social estejam presentes nos territórios, existem situações em que a instituição, com suas ferramentas legais, não pode amparar a população por não conseguir reconhecer os agravamentos que fogem dos mecanismos presentes nas ofertas dos serviços. As demandas estão em constantes mudanças e, muitas vezes, a oferta disponível por meios oficiais não consegue identificá-las e acaba não contemplando ocorrências mais subjetivas que se apresentam no território. Desta forma, tendo em vista a necessidade de aproximação e compreensão da demanda do público usuário dos serviços de Assistência Social, será dada maior ênfase no instrumento de gestão: Vigilância Socioassistencial.

Em 2011, com a alteração do artigo $2^{\circ}$ da LOAS, a Vigilância passa a adquirir maior visibilidade e importância, já que esse instrumento de gestão visa à análise territorial e à capacidade protetiva das famílias e nela a ocorrência de vulnerabilidades, ameaças, vitimizações e danos.

Para concretizar essa importância, no ano de 2012, a nova Norma Operacional Básica do SUAS (NOB-SUAS/2012) é publicada, trazendo uma nova maneira de avaliar o nível de adequação da gestão dos municípios, tal como destacar o papel da vigilância, ampliando ainda mais sua conceituação e abrangência que também determina sua estruturação e/ou implementação, que será melhor discutida no próximo item. No mesmo ano, os procedimentos e funções que ocorreram desde a implantação do SUAS são atualizados, adaptando e readequando a estrutura para garantir continuidade desse novo processo e ferramenta de gestão.

Foram anos de luta e mudanças de governo que a Assistência Social precisou (e ainda precisa) para conquistar um mínimo de ferramentas e instrumentos que auxiliam à gestão dos serviços. Ainda há grandes desafios a serem superados no âmbito da gestão dos serviços, tanto no fluxo do trabalho, na manipulação das informações socioeconômicas que auxiliam as 
tomadas de decisão, como na alimentação dos sistemas que subsidiam a modelagem e o aprimoramento das informações.

Consideram-se que as mudanças foram significativas e é a partir dessa nova realidade que se afirma a necessidade de aproximação ao cotidiano da população, pois é na escala mais próxima da realidade do cidadão que se torna possível analisar, avaliar e tomar decisões pautadas em informações coerentes às demandas sociais.

Além das informações socioeconômicas que são trabalhadas nas gerências das Secretarias de Assistência Social de todo o Brasil, os serviços do CRAS (Centro de Referência da Assistência Social) ou CREAS (Centro de Referência Especializado da Assistência Social) adquirem um papel fundamental na construção desse tipo de gestão, já que são estruturas prediais descentralizadas localizadas nos territórios próximos à população, ou seja, a aproximação à realidade é viabilizada por essas estruturas situadas nos territórios de vivência.

O CRAS é uma unidade de proteção social básica do SUAS e tem por objetivo prevenir a ocorrência de situações de vulnerabilidade e riscos sociais nos territórios. É a referência para o desenvolvimento dos serviços socioassistenciais de proteção no seu território de abrangência. O CRAS é um ponto importante no território porquê concretiza as pontes de ações políticas entre as diferentes escalas de governo e, ao mesmo tempo, tem autonomia para desenvolver todas as fases das políticas públicas (LINDO, 2011). Para que tenha oferta de serviços coerentes às demandas do território do CRAS é preciso uma boa compreensão da realidade do seu entorno, assim como conhecimento das famílias que nele vive, suas necessidades e potencialidades.

Todavia, a NOB-SUAS admite:

[...] que os CRAS sejam instalados, prioritariamente, em territórios com maior concentração de famílias com renda per capita mensal de até $1 / 2$ salário mínimo, uma vez que as vulnerabilidades sociais podem ser agravadas pela situação de empobrecimento das famílias. Em geral, territórios com concentração de famílias pobres são mais vulneráveis pois, desprovidos de serviços, o que evidencia a necessidade de uma maior atenção do Estado (BRASIL, 2009).

Salienta-se que metodologias que auxiliam a gestão a levantar informações têm de ser criadas mesmo que não atinjam diretamente à necessidade encontrada. Se há informações de difícil mensuração ou que não dispõe de estatísticas, é necessário um maior aprofundamento e criação de ações alternativas para se aproximar da população que possui perfil similar às demandas. Nesse caso, o MDS apropriou-se dos dados de renda supondo que essa informação poderia evidenciar ou, no mínimo, se aproximar das pessoas que sofrem de diversas situações que não podem se enquadrar em dados estimáveis. É a partir da busca por 
informações mais específicas e detalhadas que surge a necessidade de novas técnicas de levantamento e sistematização dos dados.

Nesse sentido, o caderno de Orientações Técnicas para Vigilância Socioassistencial expõe:

\footnotetext{
O desenvolvimento de capacidades de planejamento e gestão torna-se crucial para o amadurecimento da assistência social como política pública setorial, a qual compete garantir ou mediar o acesso aos direitos sociais específicos. Nesse contexto, os processos de produção, análise e utilização de informações ganham relevância na medida em que possibilitam qualificar a intervenção dos agentes públicos de forma que suas ações produzam processos e resultados mais condizentes com as expectativas e necessidades da população em geral e, em particular, dos segmentos sociais mais vulneráveis (BRASIL, 2013, p. 7).
}

A Vigilância pode ser capaz de aumentar a percepção do gestor sobre os territórios, pode ampliar a capacidade de proteção e defesa de direitos inerentes à noção do SUAS, de onde vem sua força como função da Política de Assistência Social e seu reconhecimento e valorização na LOAS, na PNAS e na NOB (BRASIL, 2013).

A Vigilância Socioassistencial tem adquirido importante papel nos últimos anos na esfera da gestão para o levantamento de dados, percepção e compreensão dos diversos territórios que tomam forma nos municípios, e tem assumido uma valiosa posição dentro da Política de Assistência Social.

\section{A Vigilância Socioassistencial como ferramenta de planejamento: Vulnerabilidade, Risco e Território}

O Estado brasileiro passou por um amplo processo de mudanças nos últimos anos quando o assunto é proteção social. Após a constituição de 1988, a Assistência Social passou a ser reconhecida como uma política pública cuja oferta passou a ser uma responsabilidade do Estado e direito de todos os cidadãos. Considerada como Política constitutiva de seguridade social, a Assistência Social entrou no mesmo campo de seguridade da Saúde e da Previdência Social.

Atualmente, a Vigilância Socioassistencial constitui-se como um dos objetivos estruturantes da política de Assistência Social. Essa concepção está presente tanto no texto da LOAS, a partir das alterações realizadas nessa normativa em 2011, quanto na PNAS e na NOB-SUAS-2012, como já afirmado anteriormente.

Após essas alterações, a Assistência Social passa a ter três objetivos: 
- A proteção social, que visa à garantia da vida, à redução de danos e à prevenção da incidência de riscos;

- A defesa de direitos, que visa a garantir o pleno acesso aos direitos no conjunto das provisões socioassistenciais;

- A Vigilância Socioassistencial, que visa a analisar territorialmente a capacidade protetiva das famílias e nela a ocorrência de vulnerabilidades, de ameaças, de vitimizações e danos (BRASIL, 2016, p. 08).

A Vigilância Socioassistencial é caracterizada como uma das funções da Política de Assistência Social e tem por objetivo apoiar as atividades de planejamento, organização e execução de ações que são desenvolvidas pela gestão dos serviços, bem como realizar o monitoramento e a avaliação do fluxo de trabalho, produzindo, sistematizando e analisando informações territorializadas. A organização da Vigilância Socioassistencial não é uma tarefa simples, exige esforço e investimento, e é nesta direção que a interdisciplinaridade com Geografia e as ferramentas de Geoprocessamento tomam um papel fundamental para a aplicabilidade da Vigilância. Contudo, é necessário aprofundar as definições, conceitos e estruturação que a Vigilância adquiriu após ser instituída.

Os conceitos que a Vigilância Socioassistencial se apropria para justificar sua ação estão apresentados nos documentos do MDS: “Orientações Técnicas da Vigilância Socioassistencial", no "Caderno 3 - CapacitaSUAS", de 2013, e no "Caderno do Aluno - Curso de atualização em Vigilância Socioassistencial do SUAS", de 2016. Esses documentos são materiais de capacitação utilizados por profissionais que atuam nos serviços e vivenciam a realidade da Secretaria.

A concepção de Vigilância Socioassistencial está fundamentada por um conjunto integrado de conceitos e categorias que procuram auxiliar, dar corpo teórico e contribuir com as ações dentro dos objetivos deste sistema aplicados ao planejamento, gestão e desenvolvimento da Política de Assistência Social. Como apontado nos artigos $1^{\circ}$ e $6^{\circ}$ da LOAS, após alteração de 2011, a Vigilância destaca três conceitos-chave para sua estruturação como ferramenta de planejamento, são eles: Vulnerabilidade, Risco e Território.

Para a Vigilância ter a efetividade no planejamento de ações estratégicas é necessário o levantamento dos dados, o reconhecimento da área, a escolha dos melhores indicadores que gerarão relatórios e diagnósticos. Mas é preciso material para esse caminho ser "guiado", ou seja, é fundamental conhecer os fatores que (re)constroem as demandas sociais que estão por trás de todo o levantamento realizado. É neste momento que se torna imprescindível a apropriação de conceitos norteadores que serão apresentados a seguir. 
Em primeiro lugar, o MDS, em uma nota técnica de 2014, traz sobre o entendimento de Vulnerabilidade as:

[...] situações que podem levar o indivíduo a exclusão social, tais como: desigualdades sociais, discriminações de qualquer espécie, falta de acesso aos serviços oferecidos pelo estado e município, entre outros. A vulnerabilidade não se restringe à percepção da pobreza, tida como posse de recursos financeiros, mas, a uma conjugação de fatores envolvendo o território, fragilidades ou carências e deficiências da oferta e acesso às políticas públicas. Identificar as situações de vulnerabilidade social e produzir informações para o enfrentamento desta demanda é uma das competências da vigilância socioassistencial (BRASIL, 2014, p.3).

A princípio é possível reconhecer a importância da produção de informações para confrontar com as demandas encontradas nesta política, tendo em conta que não se limita a pobreza. Assim, a Assistência Social deve compreender o aspecto multidimensional presente no conceito de vulnerabilidade social, não a restringindo à percepção de pobreza, tida como posse de recursos financeiros, embora a insuficiência de renda seja obviamente um importante fator de vulnerabilidade. A Vulnerabilidade, sendo entendida não só como escassez de renda, mas como uma conjugação de diversos fatores, estimula a compreensão e coloca questões que estabelecem novas medidas e novos levantamentos de informações e/ou indicadores que viabilizam resultados mais objetivos para cada tipo de demanda específica. Com isso, o olhar para a necessidade de cada cidadão passa a ganhar maior abrangência.

Na mesma linha de raciocínio, o segundo conceito, o de Risco, é utilizado por diversas áreas do conhecimento e tem aplicações variadas no âmbito da política pública. O Risco pode ser interpretado a partir de dois aspectos: a) como um acontecimento que tem a probabilidade de acontecer; b) um evento que tem a possibilidade de provocar um perigo imediato ou não. Dessa forma, o levantamento de indicadores precisos, nesse caso, vem auxiliar a prevenção de que aconteçam situações que o MDS compreende como Risco.

Para a assistência social, portanto, a operacionalização do conceito de risco exige a definição do conjunto de eventos em relação aos quais lhe compete diretamente desenvolver esforços para prevenir, enfrentar e reduzir seus agravos. Com relação a esses eventos é necessário desenvolver estudos que permitam algum tipo de mensuração e monitoramento da sua incidência ou da probabilidade de sua ocorrência (BRASIL, 2016, p. 19).

Com isso, utilizando como base o PNAS, é possível definir, no âmbito da Assistência Social, as situações que são entendidas como risco:

- Situações de violência intrafamiliar; negligência; maus tratos; violência, abuso e exploração sexuais; trabalho infantil; discriminação por gênero, etnia ou qualquer outra condição ou identidade. 
- Situações que denotam a fragilização ou rompimento de vínculos familiares ou comunitários, tais como vivência em situação de rua; afastamento de crianças e adolescentes do convívio familiar em decorrência de medidas protetivas; atos infracionais de adolescentes com consequente aplicação de medidas socioeducativas; privação do convívio familiar ou comunitário de idosos, crianças ou pessoas com deficiência em instituições de acolhimento; qualquer outra privação do convívio comunitário vivenciada por pessoas dependentes (crianças, idosos, pessoas com deficiência), ainda que residam com a própria família (BRASIL, 2016, p. 20).

Todas essas situações podem e devem ser prevenidas ou até mesmo enfrentadas com o escopo de serem minimizadas, mas para que isso ocorra é preciso que a política de Vigilância Socioassistencial compreenda o território que atua, e para ter essa percepção é necessário realizar o levantamento dos dados específicos aos eventos mencionados para obter informações que indique o caminho mais viável para realizar o planejamento e a gestão do território.

Porém, antes desse processo, é preciso compreender conceitualmente como a Política de Assistência Social está interpretando o Território. É nessa direção que o MDS coloca o conceito Território como mais um dos conceitos-chave para a compreensão do objetivo da Vigilância Socioassistencial. É possível afirmar que este conceito para Política de Assistência Social tem tomado alguns caminhos que se associam ao discutido atualmente na Geografia ao se apropriar de concepções de Geógrafos como Santos (1999), Haesbaert (2016), Saquet (2018), mais uma vez afirmando a importância da comunicação interdisciplinar entre a Geografia e o Serviço Social.

Dessa forma, a Política tem se aproximado da categoria geográfica procurando enfoques físicos/políticos, mas principalmente enfoques de âmbito sociocultural, que traz a discussão partindo dos atores que estão (re)construindo e modelando o Território constantemente. Na ótica da Política de Assistência Social, o olhar não é isolado, e, contudo, é possível agregá-lo a essa categoria geográfica complexa e ao mesmo tempo esclarecedora.

Pode-se constatar a associação da categoria geográfica nos documentos da Política de Assistência, nos quais, de acordo com a Nota Técnica do MDS de 2014, o território:

[...] pode ser definido como um espaço geográfico (bairros, vilas, municípios etc.) onde as pessoas vivem e convivem, se tornando suscetíveis aos acontecimentos políticos, econômicos e sociais, os quais podem provocar transformações na vida destes indivíduos, levando-os às situações de risco e vulnerabilidade social e consequentemente como objeto de intervenção da Política de Assistência Social (BRASIL, 2013, p.11).

Para completar e esclarecer que a noção territorial da Política não se limita apenas às articulações e mudanças constantes dentro do território, a discussão vai além, faz relação 
com as pessoas e a carga cultural e pessoal que carregam, e com o cruzamento da trajetória dos lugares e a carga cultural que os mesmos possuem.

\begin{abstract}
Tomando como referência as topografias sociais dos territórios de vida e de vivência, que revelam/escondem perfis de famílias e territórios, se sabe que esses universos trazem consigo histórias de vida, experiências travadas ao longo do tempo, particularidades. Trajetórias de famílias que entrecruzam com trajetórias dos lugares. Entendendo a Vigilância Socioassistencial associada à proteção social e à defesa de direitos, a dimensão dessas trajetórias cruzadas pode contribuir na compreensão das particularidades que permeiam as condições de vida, e que terminam definindo ou explicando processos referenciais à política de assistência social, como vulnerabilidade e riscos sociais (BRASIL, 2013, p.85).
\end{abstract}

Fica evidente que a Política de Assistência Social ao se utilizar do conceito de território, teoricamente, o considera como um espaço vivo que está em constante mudança e sofre modificações de acordo com os eventos que seus atores provocam, sejam eles políticos, econômicos ou sociais. O conceito de território na Política de Assistência busca compreender as particularidades mais próximas dos cidadãos para, depois disso, tomar decisões pautadas em seus objetivos específicos.

O território, simultaneamente contém a natureza da pluralidade dos lugares, (BECATTINI, 2009). E essa compreensão do território-lugar é imprescindível para o entendimento da consciência de classe e de lugar, sem a costumeira separação entre sociedade e natureza, tempo e espaço, território e lugar influenciando a práxis de transformação social e territorial em favor do povo, das suas necessidades, aspirações e dos seus desejos (SAQUET, 2018, p.489).

Em ressonância com o debate territorial, a Vigilância Socioassistencial visa detectar e compreender as situações de precarização e de agravamento das vulnerabilidades que afetam os territórios, prejudicam e colocam em risco a sobrevivência e a dignidade dos cidadãos. A Vigilância apoia as atividades de planejamento, organiza e executa ações desenvolvidas pela gestão, bem como monitora o fluxo de trabalho no âmbito das informações territorializadas. Para cumprir com esses objetivos, como facilitadora da Proteção Social e Defesa de Direitos, a Vigilância Socioassistencial:

- produz e sistematiza informações, constrói indicadores e índices territorializados das situações de risco e vulnerabilidade social, que incidem sobre famílias e sobre os indivíduos nos diferentes ciclos de vida;

- monitora a incidência das situações de violência, negligência e maus tratos, abuso e exploração sexual, que afetam famílias e indivíduos, com especial atenção para aquelas em que são vítimas crianças, adolescentes, idosos e pessoas com deficiência. 
- monitora os padrões de qualidade dos serviços de Assistência Social, com especial atenção para aqueles que operam na forma de albergues, abrigos, residências, semiresidências, moradias provisórias para os diversos segmentos etários;

- auxilia a identificação de potencialidades dos territórios e das famílias neles residentes (BRASIL, 2013, p.10).

É possível identificar que, em seus propósitos, a implantação de um sistema que visa a Vigilância Socioassistencial está intimamente relacionada com o planejamento e a organização das informações em geral. Deste modo, pretende viabilizar o monitoramento e a incidência de situações de violência, identificação de pessoas com deficiência ou abandono, identificação das deficiências ou das potencialidades presentes nos territórios de vivência.

\section{Considerações finais}

A política pública de natureza social é o instrumento capaz de mudar o cenário já presente no país. Porém, elaborar políticas públicas dentro do contexto social sempre foi tarefa difícil, assim como lidar com o interesse político e financeiro é um desafio no Brasil. Presidente, governadores, prefeitos, gestores, representantes etc., em sua grande maioria interessados no desenvolvimento econômico e nos resultados imediatos, são o maior empecilho para a aplicação das políticas sociais a longo prazo e realmente efetivas. A política pública estratégica é o modo mais eficaz de promover a ascensão social daqueles que já estão marginalizados e em situação de extrema vulnerabilidade. É com essa demanda que acreditase no poder das políticas sociais e nas ferramentas que dela surgem, pois existem métodos capazes de viabilizar uma reforma social. Essas ferramentas aparecem para suprir uma falta: a falta que os serviços sociais encontram no seu cotidiano.

Como é possível observar, o artigo traz uma revisão histórica do lugar da Vigilância Socioassistencial na Política de Assistência Social e evidencia espontaneamente a conjuntura do papel da Política de Assistência Social no Estado. Com isso, pode-se afirmar que os estudos e levantamentos interdisciplinares realizados em torno das políticas sociais, sejam históricas ou pontuais, vão sempre trazer a projeção do Estado e a responsabilidade que o mesmo vai carregar com a relevância em (re)conhecer constantemente o saber local.

Para a Política de Assistência Social, a relevância em conhecer seus territórios de atuação e vivência é indispensável para efetividade dos direcionamentos e articulações da política. Quando se estuda a Vigilância Socioassistencial, automaticamente encontra-se mais perguntas que respostas, pois quando é trazido a discussão do saber local, do território usado ou a valorização das territorialidades para pautar tomadas de decisão, os papéis que 
fundamentam a ciência se invertem e passam a valorizar o saber subjetivo e diversificado dos sujeitos que constroem cotidianamente seu território. As ferramentas de participação social e os métodos que traduzem o conhecimento popular em medidas efetivas de gestão necessitam ser aprimoradas e, por esse motivo, antes de qualquer consideração, aponta-se a importância em dar continuidade para atividades de pesquisa que promovem um aprimoramento do olhar da gestão para os territórios e, assim, estimular o emprego de metodologias que pautam o uso do conhecimento local para dentro dos órgãos públicos com o intuito de começar a "ouvir" quem realmente conhece o território e, dessa forma, tomar decisões amparadas por um conhecimento empírico, efetivando os próprios objetivos da Vigilância Socioassistencial.

\section{Referências:}

ANTONELLO, I. T. O entrelaçamento entre a descentralização das políticas públicas e as desigualdades territoriais no Paraná. In: VI SIMPGEO - Simpósio Paranaense de Pósgraduação e Pesquisa em Geografia - Ciência, Sociedade e Tecnologia na Perspectiva da Análise Geográfica. Guarapuava, 2012, Anais [...] Guarapuava: Ed. Da UNICENTRO, 2012. v.I, p.831 - 846. CD ROM

BRASIL. Ministério do Desenvolvimento Social e Combate à Fome e a Miséria (MDS), Norma Operacional Básica NOB-SUAS. Brasília, DF, julho 2004.

BRASIL. Ministério do Desenvolvimento Social e Combate à Fome e Secretaria Nacional de Assistência Social. Política Nacional de Assistência Social. Brasília, 2004.

BRASIL. Orientações técnicas para o Centro de Referência da Assistência Social - CRAS / Ministério do Desenvolvimento Social e Combate à Fome. - 1. Ed. - Brasília, 2009.

BRASIL. Secretaria Nacional de Assistência Social. Ministério do Desenvolvimento Social e Combate à Fome e a Miséria (MDS), Norma Operacional Básica NOB-SUAS. Brasília, DF, 2012.

BRASIL. Orientações Técnicas da Vigilância Socioassistencial. Brasília, DF: Ministério do Desenvolvimento Social e Combate à Fome. Secretaria Nacional de Assistência Social, 2013.

BRASIL. Orientações Técnicas da Vigilância Socioassistencial. Ministério do Desenvolvimento Social e Combate à Fome/Secretaria Nacional de Assistência Social. Nota Técnica. № 01. Curitiba, PR. Junho de 2014.

BRASIL. Ministério do Desenvolvimento Social e Agrário; Universidade Federal do Rio Grande do Sul. Curso de atualização em vigilância sociassistencial do SUAS. - Brasília, DF: MDSA, Secretaria de Avaliação e Gestão da Informação, Secretaria Nacional de Assistência Social. Centro de Estudos Internacionais sobre o Governo, 2016. 
BRASIL, Constituição da República Federativa do Brasil de 1988. Disponível em <http://www.presidencia.gov.br>. Acesso em: agosto de 2017.

GIAQUETO, A. A descentralização e a intersetorialidade na política de assistência social. Revista serviço social \& saúde, Unicamp Campinas, v. Ix, n. 10, dez. 2010. p. 79-102.

LINDO, P. V. de F. Geografia e política de assistência social: territórios, escalas e apresentações cartográficas para políticas públicas. São Paulo: Cultura Acadêmica, 2011.

OLIVEIRA, I. M. de. Política social, assistência social e cidadania: algumas aproximações acerca do seu significado na realidade brasileira. Revista Desafios Sociais, Revista do Programa de Pós-Graduação em Serviço Social da Universidade Federal do Rio Grande do Norte (UFRN), Natal, ano I, n.2, set. 2003. Disponível em:

<http://www.cpihts.com/2003 10 19/Iris\%20Oliveira.htm\# edn2>. Acesso em: agosto de 2017

PEREIRA, L. D. 2010. Políticas Públicas de Assistência Social brasileira: avanços, limites e desafios. Centro Português de Investigação em História e Trabalhos Social. Disponível em: <http://www.cpihts.com/PDF02/Larissa\%20Dahmer\%20Pereira.pdf >. Acesso em: agosto de 2017.

SAQUET, M. A. A descoberta do território e outras premissas do desenvolvimento territorial. Revista Brasileira de Estudos Urbanos Regionais, São Paulo, V.20, N.20, N.3, o 479-505, 2018.

SANTOS, W. G. dos, Cidadania e Justiça: a política social na ordem brasileira. Rio de Janeiro: Ed. Campos, 1979, 138 p. 